\title{
PENGENDALIAN KUALITAS GENTENG BETON MENGGUNAKAN METODE STATISTICAL QUALITY CONTROL
}

\author{
Digitha Oktaviani Putri ${ }^{*}$, Marcelino Soares ${ }^{2}$ \\ 1,2Jurusan Teknik Industri ,Universitas Merdeka Malang \\ *Korespondensi Penulis, E-mail: digitha.oktaviani@unmer.ac.id \\ Diterima : 22 April 2019 \\ Disetujui : 30 April 2019 \\ Direvisi : 26 April 2019
}

\begin{abstract}
Abstrak
Pengendalian kualitas merupakan usaha untuk mempertahankan kualitas dari produk yang dihasilkan agar sesuai dengan spesifikasi yang telah ditetapkan produsen. Penelitian ini dilakukan untuk menganalisa produk cacat dan penyebab terjadinya kecacatan dengan menggunakan statistical quality control dari produk genteng beton tipe genteng flat. Berdasarkan pengolahan data dengan checksheet dan histogram dapat diketahui bahwa cacat pada produk genteng flat yaitu cacat retak rambut $(56,29 \%)$ dan cacat patah $(43,71 \%)$. Pada peta kendali $\mathrm{p}$ menunjukkan bahwa semua data berada dalam batas kendali dan untuk mengetahui penyebab terjadinya cacat dilakukan analisis dengan diagram sebab akibat, kemudian disusun usulan perbaikan kualitas untuk dapat memperbaiki tingkat kecacatan produk dan menjadi masukan untuk peningkatan kualitas. Hal penting yang patut diperhatikan dan menjadi masukan dalam perbaikan kualitas adalah faktor manusia yang memerlukan pengawasan dan pelatihan agar dapat memahami proses produksi dengan baik dan meminimalkan produk cacat.
\end{abstract}

Kata kunci: kualitas,pengendalian kualitas statistik,peta kendali p, diagram sebab akibat

\section{Pendahuluan}

Genteng Beton X Malang merupakan perusahaan perseorangan yang didirikan pada tahun 1990 dimana pada awalnya perusahaan hanya memproduksi tegel. Seiring dengan perkembangan dan perimintaan pasar, perusahaan kemudian memproduksi genteng, paving dan batako. Perusahaan memproduksi 1000 genteng tiap hari untuk masing-masing jenis genteng flat, genteng nusantara dan genteng royal. Berdasarkan pengamatan yang dilakukan terdapat jenis kecacatan yang ditemukan pada produk genteng yaitu retak rambut dan patah.

Dalam proses produksinya perusahaan telah melakukan pengendalian kualitas yang dilakukan secara manual, namun masih terdapat kerusakan produk. Berdasarkan masalah yang dihadapi maka perlu dilakukan tindakan pengendalian kualitas produk untuk mengetahui penyebab masalah dan menemukan solusi perbaikan dari permasalahan tersebut.

Kualitas didefinisikan sebagai jumlah dari atribut atau sifat-sifat sebagaimana dideskripsikan didalam produk (dari jasa) yang bersangkutan [1].Tiap produk mempunyai sejumlah unsur yang bersama-sama menggambarkan kecocokan penggunaannya. Parameter-parameter ini biasanya dinamakan ciri-ciri kualitas. Ciri-ciri kualitas ada beberapa jenis: [2]

1. Fisik. Panjang,berat, voltase,kekentalan

2. Indera. Rasa, penampilan,warna

3. Orientasi waktu. Keandalan (dapat dipercaya), dapatnya dipelihara, dapatnya dirawat

Ditinjau dari sudut pandang produsen, kualitas dapat diartikan sebagai kesesuaian dengan spesifikasinya. Suatu produk akan dinyatakan berkualitas oleh produsen apabila produk tersebut telah sesuai dengan spesifikasinya [3].

Pengendalian kualitas dalam arti menyeluruh adalah merupakan usaha untuk mempertahankan mutu kualitas dari barang yang dihasilkan agar sesuai dengan 
spesifikasi produk yang telah ditetapkan berdasarkan kebijaksanaan pimpinan perusahaan [4]. Faktor-faktor yang mempengaruhi pengendalian kualitas yang dilakukan perusahaan adalah: [5]

1. Kemampuan proses. Batas-batas yang ingin dicapai haruslah disesuaikan dengan kemampuan proses yang ada. Tidak ada gunanya mengendalikan suatu proses dalam batas-batas yang melebihi kemampuan atau kesanggupan proses yang ada.

2. Spesifikasi yang berlaku, hasil produksi yang ingin dicapai harus dapat berlaku, bila ditinjau dari segi kemampuan proses dan keinginan atau kebutuhan konsumen yang ingin dicapai dari hasil produksi tersebut. Dapat dipastikan dahulu apakah spesifikasi tersebut dapat berlaku sebelum pengendalian kualitas pada proses dapat dimulai.

3. Tingkat ketidaksesuaian yang dapat diterima. Tujuan dilakukan pengendalian suatu proses adalah dapat mengurangi produk yang berada di bawah standar seminimal mungkin. Tingkat pengendalian yang diberlakukan tergantung pada banyaknya produk yang berada di bawah standar.

4. Biaya kualitas, sangat mempengaruhi tingkat pengendalian dalam menghasilkan produk dimana biaya mempunyai hubungan yang positif dengan terciptanya produk yang berkualitas.

Pengendalian kualitas secara statistik dapat digunakan untuk menemukan kesalahan produksi yang mengakibatkan produk tidak baik, sehingga dapat diambil tindakan lebih lanjut untuk mengatasinya. Statistical Quality Control (Pengendalian Kualitas Statistik) adalah teknik yang digunakan untuk mengendalikan dan mengelola proses baik manufaktur maupun jasa melalui penggunaan metode statistik. Pengendalian kualitas statistik merupakan teknik penyelesaian masalah yang digunakan untuk memonitor, mengendalikan, menganalisis, mengelola dan memperbaiki produk dan proses menggunakan metode-metode statistik [6].

Pengendalian kualitas secara statistik mempunyai tujuh alat statistik utama yang dapat digunakan sebagai alat bantu untuk mengendalikan kualitas yaitu check sheet, histogram, control chart, diagram pareto, diagram sebab akibat, scatter diagram dan desain eksperimen [7].

\section{Metode Penelitian}

Pada penelitian ini menggunakan data primer dan sekunder untuk dapat melakukan analisis terhadap pengendalian kulitas genteng. Data primer didapatkan dari data hasil pengamatan dan wawancara dengan pihak perusahaan mengenai proses produksi. Sedangkan data sekunder adalah data yang didapatkan langsung dari perusahaan yang berasal dari dokumen, bukti atau cacatan. Data sekunder yang dibutuhkan dalam penelitian adalah data mengenai jumlah produksi dan jumlah kerusakan produk tiap hari. Jenis kerusakan yang diamati adalah cacat retak rambut dan cacat patah.

\subsection{Analisa Data}

Pada penelitian ini proses pengolahan data yang dilakukan adalah sebagai berikut:

1. Mengumpulkan data jumlah produksi dan kerusakan produk tiap hari serta melakukan wawancara untuk mendapatkan informasi tambahan mengenai proses produksi dan data lain yang dapat menunjang penelitian. Data jumlah produksi dan kerusakan produk disajikan dalam tabel dengan menggunakan checksheet.

2. Membuat histogram, yang berupa alat penyajian data secara visual berbentuk grafik balok yang memperlihatkan distribusi nilai yang diperoleh dalam bentuk angka. [6] 
3. Membuat peta kendali $p$ dengan langkah-langkah sebagai berikut:

a. Menghitung persentase kerusakan

Rumus yang digunakan: $p=\frac{n p}{n}$

Keterangan:

$\mathrm{np}=$ jumlah gagal dalam sub grup

$\mathrm{n}=$ jumlah yang diperiksa dalam sub grup

b. Menghitung central line (CL)

Central line merupakan rata-rata kerusakan produk $(\bar{p})$

Rumus yang digunakan: $C L=\bar{p}=\frac{n p}{n}$

Keterangan:

$\mathrm{np}=$ jumlah total yang rusak

$\mathrm{n}=$ jumlah total yang diperiksa

c. Menghitung batas kendali atas atau Upper Control Limit (UCL)

Rumus yang digunakan: $U C L=\bar{p}+3 \frac{\sqrt{\bar{p}(1-\bar{p})}}{n}$

Keterangan:

$\bar{p}=$ rata-rata ketidaksesuaian produk

$n=$ jumlah produksi

d. Menghitung batas kendali bawah atau Lower Control Limit (LCL)

Rumus yang digunakan: $U C L=\bar{p}-3 \frac{\sqrt{\bar{p}(1-\bar{p})}}{n}$

Keterangan:

$\bar{p}=$ rata-rata ketidaksesuaian produk

$n=$ jumlah produksi

4. Membuat diagram sebab akibat (fishbone diagram) untuk mencari faktor penyebab kerusakan.

5. Membuat usulan perbaikan.

6. Analisa dan pembahasan hasil penelitian.

\section{Hasil dan Pembahasan}

Berdasarkan hasil pengumpulan data yang diperoleh data produksi dan jumlah genteng cacat pada bulan Mei 2018 untuk masing-masing jenis genteng flat, genteng nusantara dan genteng royal sebagai berikut:

Tabel 1. Data Jumlah Produk Cacat Produk Genteng bulan Mei 2018

\begin{tabular}{|c|c|c|c|c|}
\hline \multirow{2}{*}{ Hari } & \multirow{2}{*}{ Total Produksi } & \multicolumn{3}{|c|}{ Jumlah Produk Cacat } \\
\cline { 3 - 5 } & & Genteng Flat & Genteng Nusantara & Genteng Royal \\
\hline 1 & Libur & - & - & - \\
\hline 2 & 1000 & 13 & 25 & 45 \\
\hline 3 & 1000 & 42 & 37 & 32 \\
\hline 4 & 1000 & 48 & 54 & 32 \\
\hline 5 & 1000 & 41 & 45 & - \\
\hline 6 & Libur & - & - & 40 \\
\hline 7 & 1000 & 38 & 32 & 35 \\
\hline 8 & 1000 & 40 & 42 & 45 \\
\hline 9 & 1000 & 32 & 33 & 29 \\
\hline 10 & Libur & - & - & 42 \\
\hline 11 & 1000 & 35 & 46 & - \\
\hline 12 & 1000 & 40 & 34 & 38 \\
\hline 13 & Libur & - & - & 43 \\
\hline 14 & 1000 & 33 & 26 & 27 \\
\hline 15 & 1000 & 38 & 38 & 32 \\
\hline 16 & 1000 & 37 & 37 & 37 \\
\hline 17 & 1000 & 42 & 32 & 49 \\
\hline 18 & 1000 & 39 & & \\
\hline
\end{tabular}




\begin{tabular}{|c|c|c|c|c|}
\hline 19 & 1000 & 41 & 29 & 39 \\
\hline 20 & Libur & - & - & - \\
\hline 21 & 1000 & 38 & 26 & 43 \\
\hline 22 & 1000 & 41 & 32 & 32 \\
\hline 23 & 1000 & 46 & 42 & 37 \\
\hline 24 & 1000 & 29 & 50 & 36 \\
\hline 25 & 1000 & 36 & 33 & 21 \\
\hline 26 & 1000 & 28 & 23 & - \\
\hline 27 & Libur & - & - & - \\
\hline 28 & 1000 & 38 & 42 & 38 \\
\hline 29 & Libur & - & - & 42 \\
\hline 30 & 1000 & 45 & 19 & 857 \\
\hline 31 & 1000 & 42 & 37 & \\
\hline Jumlah & 24000 & 902 & 863 & \\
\hline
\end{tabular}

Keterangan: jumlah produksi genteng sebanyak 1000buah genteng perhari berlaku untuk masig-masing jenis genteng

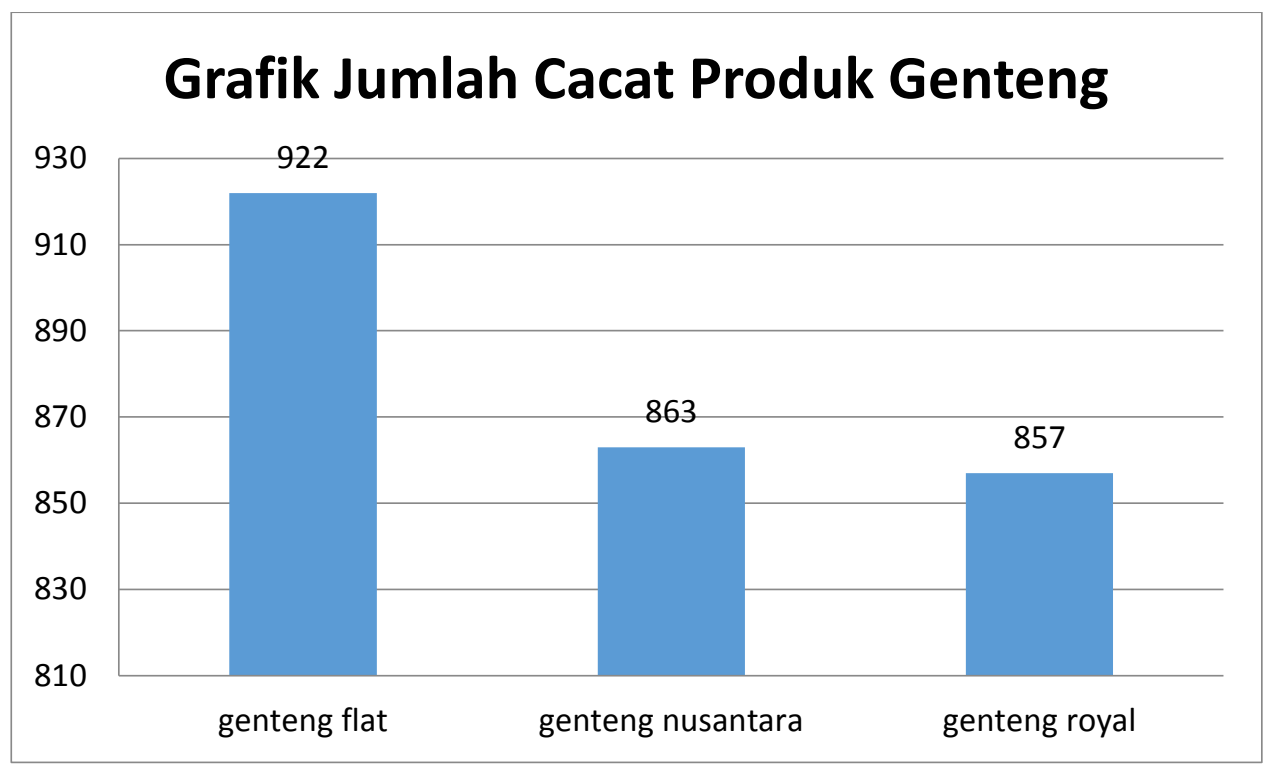

Gambar 1. Grafik jumlah cacat produk genteng

Berdasarkan dari tabel data produksi produk cacat serta dari grafik diatas, terlihat bahwa dari 3 jenis genteng yang diproduksi, jenis genteng yang paling banyak jumlah cacat nya adalah jenis genteng flat dibandingkan dengan jenis genteng nusantara dan genteng royal. Sehingga yang dianalisa pada penelitian ini adalah jenis genteng flat.

\subsection{Check Sheet}

Check sheet digunakan untuk menghitung kecacatan yang terjadi dan digunakan dalam pengumpulan data. Dari data kecacatan genteng flat, terdapat dua jenis cacat yaitu cacat retak rambut dan cacat patah. Data tersebut ditampilkan sebagai berikut:

Tabel 2. Data Jumlah Produk Cacat Genteng Flat bulan Mei 2018

\begin{tabular}{|c|c|c|c|c|}
\hline \multirow{2}{*}{ Hari } & \multirow{2}{*}{$\begin{array}{c}\text { Total } \\
\text { Produksi }\end{array}$} & \multicolumn{2}{|c|}{ Jenis Cacat } & \multirow{2}{*}{ Jumlah } \\
\cline { 3 - 5 } & Libur & - & - & - \\
\hline 1 & 1000 & 17 & 16 & 33 \\
\hline 2 & 1000 & 27 & 15 & 42 \\
\hline 3 & 1000 & 27 & 21 & 48 \\
\hline 4 & 1000 & 30 & 11 & 41 \\
\hline 5 & & & & \\
\hline
\end{tabular}




\begin{tabular}{|c|c|c|c|c|}
\hline 6 & Libur & - & - & - \\
\hline 7 & 1000 & 18 & 20 & 38 \\
\hline 8 & 1000 & 22 & 18 & 40 \\
\hline 9 & 1000 & 20 & 12 & 32 \\
\hline 10 & Libur & - & - & - \\
\hline 11 & 1000 & 16 & 19 & 40 \\
\hline 12 & 1000 & 25 & 15 & - \\
\hline 13 & Libur & - & - & 33 \\
\hline 14 & 1000 & 20 & 13 & 38 \\
\hline 15 & 1000 & 30 & 8 & 37 \\
\hline 16 & 1000 & 17 & 20 & 42 \\
\hline 17 & 1000 & 18 & 24 & 39 \\
\hline 18 & 1000 & 20 & 19 & 41 \\
\hline 19 & 1000 & 17 & 24 & 38 \\
\hline 20 & Libur & - & - & 41 \\
\hline 21 & 1000 & 29 & 9 & 46 \\
\hline 22 & 1000 & 19 & 22 & 29 \\
\hline 23 & 1000 & 29 & 17 & 36 \\
\hline 24 & 1000 & 20 & 9 & 28 \\
\hline 25 & 1000 & 20 & 16 & - \\
\hline 26 & 1000 & 17 & 11 & 38 \\
\hline 27 & Libur & - & - & - \\
\hline 28 & 1000 & 13 & 25 & 45 \\
\hline 29 & Libur & - & - & 42 \\
\hline 30 & 1000 & 30 & 15 & 922 \\
\hline 31 & 1000 & 18 & 24 & 403 \\
\hline Jumlah & 24000 & 519 & & \\
\hline
\end{tabular}

Berdasarkan tabel diatas menunjukkan bahwa jumlah produk cacat pada genteng flat sebanyak 902 produk cacat yang terdiri dari 502 produk cacat retak rambut dan 393 produk cacat patah.

\subsection{Histogram}

Histogram digunakan untuk menunjukkan cacat terbesar.

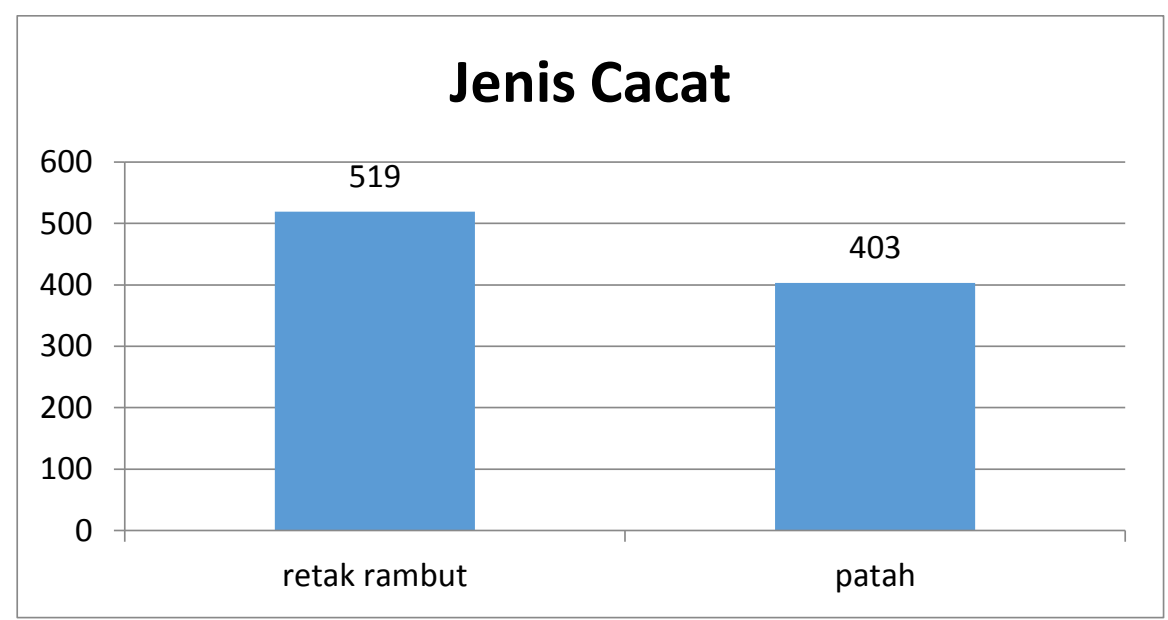

Gambar 2. Histogram Jenis Cacat Produk Genteng Flat

Pada histogram diatas diantara dua jenis cacat pada genteng flat dapat diketahui jika jenis cacat yang paling besar adalah jenis cacat retak rambut yaitu sebanyak 519 produk cacat $(56,29 \%)$ daripada jenis cacat patah sebanyak 403 produk cacat $(43,71 \%)$. 


\subsection{Peta Kendali $p$}

Peta kendali $p$ digunakan untuk membantu memonitor dan mengevaluasi apakah proses berada dalam kendali kualitas atau tidak. Tahapan dalam membuat peta kendali $p$ adalah sebagai berikut:

1. Peta kendali p untuk jenis cacat retak rambut

a. Menghitung persentase kerusakan

Rumus yang digunakan: $p=\frac{n p}{n}$

Hasil perhitungan sebagai berikut:

Tabel 3. Persentase Produk Genteng Flat dengan Jenis Cacat Retak Rambut

\begin{tabular}{|c|c|c|c|}
\hline Hari & Total Produksi & Cacat Retak rambut & Persentase \\
\hline 1 & Libur & - & - \\
\hline 2 & 1000 & 17 & 0,017 \\
\hline 3 & 1000 & 27 & 0,027 \\
\hline 4 & 1000 & 27 & 0,027 \\
\hline 5 & 1000 & 30 & 0,030 \\
\hline 6 & Libur & - & - \\
\hline 7 & 1000 & 18 & 0,018 \\
\hline 8 & 1000 & 22 & 0,022 \\
\hline 9 & 1000 & 20 & 0,020 \\
\hline 10 & Libur & - & - \\
\hline 11 & 1000 & 16 & 0,016 \\
\hline 12 & 1000 & 25 & 0,025 \\
\hline 13 & Libur & - & \\
\hline 14 & 1000 & 20 & 0,020 \\
\hline 15 & 1000 & 30 & 0,030 \\
\hline 16 & 1000 & 17 & 0,017 \\
\hline 17 & 1000 & 18 & 0,018 \\
\hline 18 & 1000 & 20 & 0,020 \\
\hline 19 & 1000 & 17 & 0,017 \\
\hline 20 & Libur & - & - \\
\hline 21 & 1000 & 29 & 0,029 \\
\hline 22 & 1000 & 19 & 0,019 \\
\hline 23 & 1000 & 29 & 0,029 \\
\hline 24 & 1000 & 20 & 0,020 \\
\hline 25 & 1000 & 20 & 0,020 \\
\hline 26 & 1000 & 17 & 0,017 \\
\hline 27 & Libur & - & - \\
\hline 28 & 1000 & 13 & 0,013 \\
\hline 29 & Libur & - & - \\
\hline 30 & 1000 & 30 & 0,030 \\
\hline 31 & 1000 & 18 & 0,018 \\
\hline Jumlah & 24000 & 519 & 0,519 \\
\hline
\end{tabular}

b. Menghitung central line (CL)

Central line merupakan rata-rata kerusakan produk $(\bar{p})$

$$
C L=\bar{p}=\frac{n p}{n}=\frac{519}{24000}=0,022
$$

c. Menghitung batas kendali atas atau Upper Control Limit (UCL)

$$
U C L=\bar{p}+3 \frac{\sqrt{\bar{p}(1-\bar{p})}}{n}=0,022+3 \frac{\sqrt{0,022(1-0,022)}}{1000}=0,035
$$

d. Menghitung batas kendali bawah atau Lower Control Limit (LCL)

$$
U C L=\bar{p}-3 \frac{\sqrt{\bar{p}(1-\bar{p})}}{n}=0,022-3 \frac{\sqrt{0,022(1-0,022)}}{1000}=0,008
$$


Berdasarkan hasil perhitungan diatas maka peta kendali $p$ yeng terbentuk untuk jenis cacat retak rambut adalah sebagai berikut:

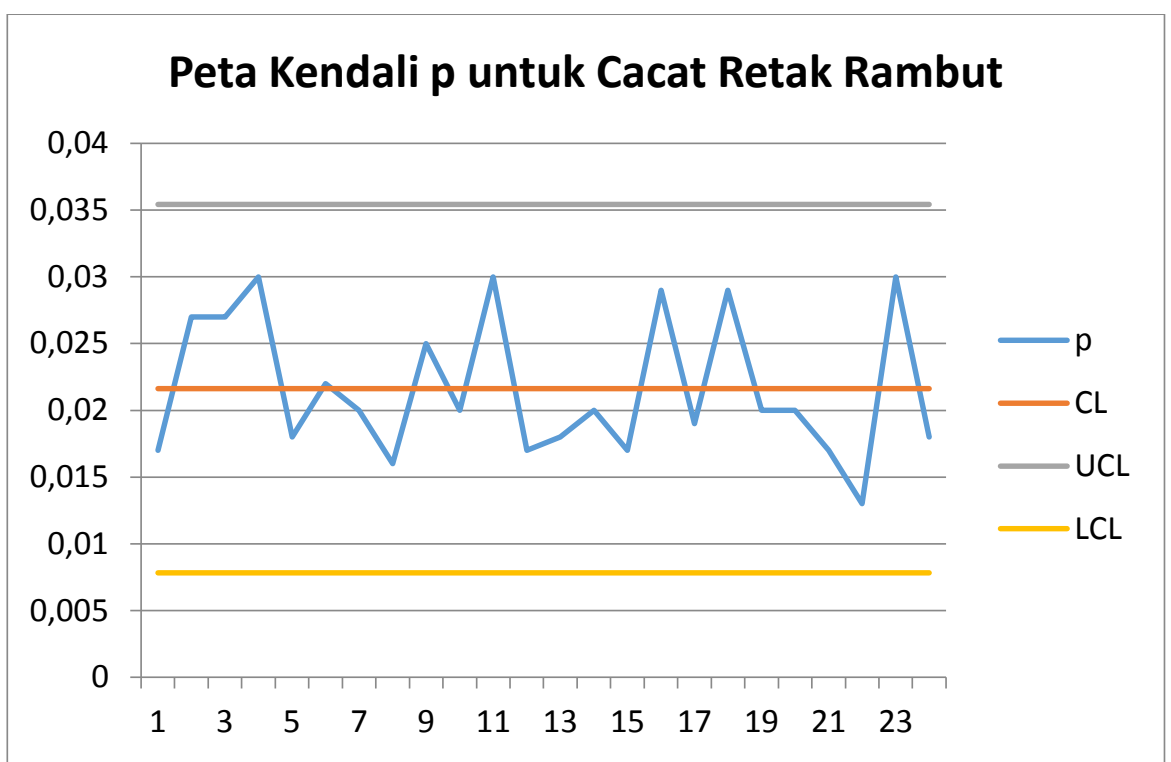

Gambar 3. Peta Kendali p untuk Jenis Cacat Retak Rambut

Berdasarkan gambar peta kendali $p$ diatas dapat diketahui bahwa semua data berada pada batas kendali.

2. Peta kendali p untuk jenis cacat patah

a. Menghitung persentase kerusakan

Rumus yang digunakan: $p=\frac{n p}{n}$

Hasil perhitungan sebagai berikut:

Tabel 4. Persentase Produk Genteng Flat dengan Jenis Cacat Patah

\begin{tabular}{|c|c|c|c|}
\hline Hari & Total Produksi & Cacat Retak rambut & Persentase \\
\hline 1 & Libur & - & - \\
\hline 2 & 1000 & 16 & 0,016 \\
\hline 3 & 1000 & 15 & 0,015 \\
\hline 4 & 1000 & 21 & 0,021 \\
\hline 5 & 1000 & 11 & 0,011 \\
\hline 6 & Libur & - & - \\
\hline 7 & 1000 & 20 & 0,020 \\
\hline 8 & 1000 & 18 & 0,018 \\
\hline 9 & 1000 & 12 & 0,012 \\
\hline 10 & Libur & - & - \\
\hline 11 & 1000 & 19 & 0,019 \\
\hline 12 & 1000 & 15 & 0,015 \\
\hline 13 & Libur & - & 0,013 \\
\hline 14 & 1000 & 13 & 0,008 \\
\hline 15 & 1000 & 8 & 0,020 \\
\hline 16 & 1000 & 20 & 0,024 \\
\hline 17 & 1000 & 24 & 0,019 \\
\hline 18 & 1000 & 19 & 0,024 \\
\hline 19 & 1000 & 24 & - \\
\hline 20 & Libur & - & 0,009 \\
\hline 21 & 1000 & 9 & 0,022 \\
\hline 22 & 1000 & 22 & 0,017 \\
\hline 23 & 1000 & 17 & 0,009 \\
\hline 24 & 1000 & 9 & 0,016 \\
\hline 25 & 1000 & 16 & \\
\hline & & & \\
\hline
\end{tabular}




\begin{tabular}{|c|c|c|c|}
\hline 26 & 1000 & 11 & 0,011 \\
\hline 27 & Libur & - & - \\
\hline 28 & 1000 & 25 & 0,025 \\
\hline 29 & Libur & - & - \\
\hline 30 & 1000 & 15 & 0,015 \\
\hline 31 & 1000 & 24 & 0,024 \\
\hline Jumlah & 24000 & 403 & 0,403 \\
\hline
\end{tabular}

b. Menghitung central line (CL)

Central line merupakan rata-rata kerusakan produk $(\bar{p})$

$$
C L=\bar{p}=\frac{n p}{n}=\frac{403}{24000}=0,017
$$

c. Menghitung batas kendali atas atau Upper Control Limit (UCL)

$$
U C L=\bar{p}+3 \frac{\sqrt{\bar{p}(1-\bar{p})}}{n}=0,017+3 \frac{\sqrt{0,017(1-0,017)}}{1000}=0,029
$$

d. Menghitung batas kendali bawah atau Lower Control Limit (LCL)

$$
U C L=\bar{p}-3 \frac{\sqrt{\bar{p}(1-\bar{p})}}{n}=0,017-3 \frac{\sqrt{0,017(1-0,017)}}{1000}=0,0046
$$

Berdasarkan hasil perhitungan diatas maka peta kendali $p$ yeng terbentuk untuk jenis cacat retak patah adalah sebagai berikut:

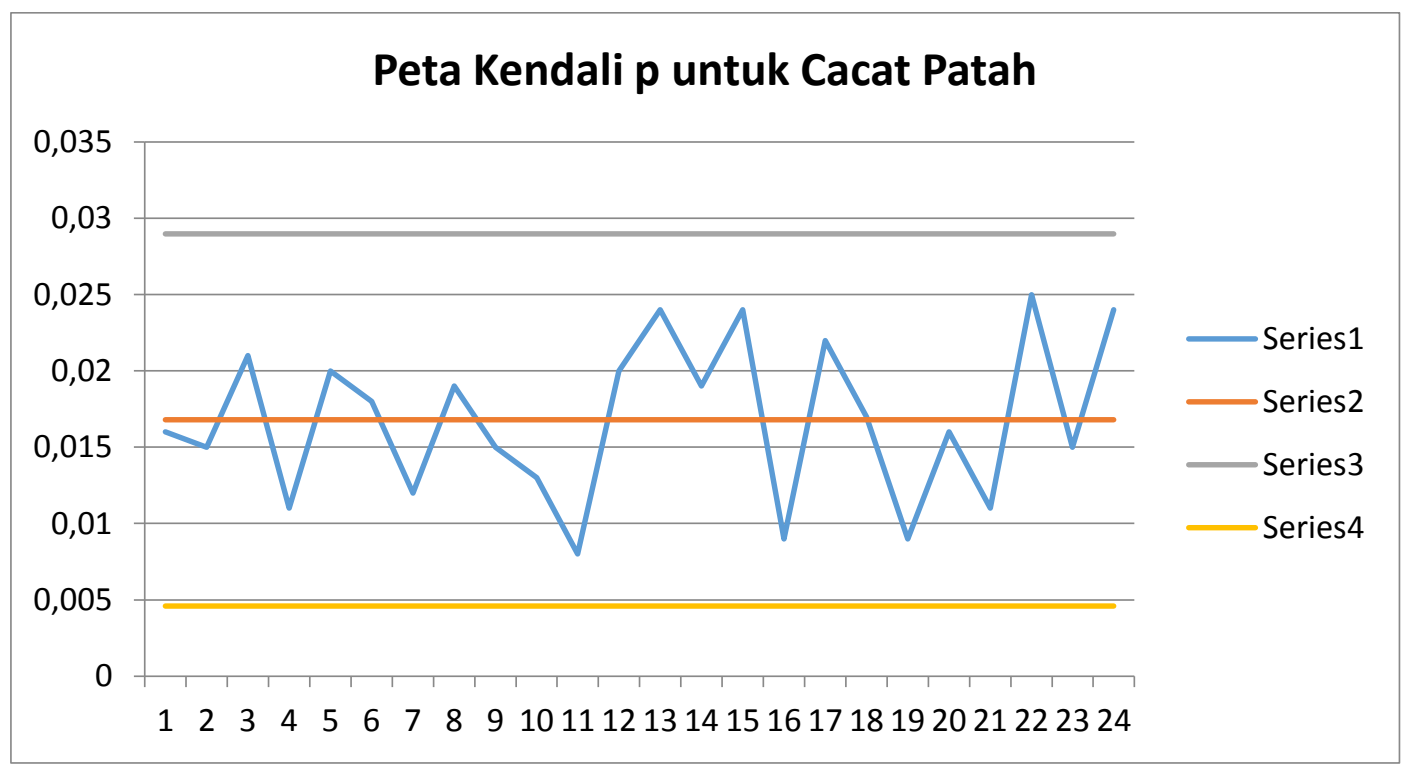

Gambar 4. Peta Kendali $p$ untuk Jenis Cacat Patah

Berdasarkan gambar peta kendali $p$ diatas dapat diketahui bahwa semua data berada pada batas kendali.

\subsection{Diagram Sebab Akibat}

Diagram sebab akibat menunjukkan hubungan antara permasalahan dengan kemungkinan penyebab permasalahan tersebut serta faktor-faktor yang mempengaruhinya. Faktor-faktor yang mempengaruhi dan menjadi penyebab kerusakan produk secara umum dapat digolongkan menjadi:

1. Man (manusia): para pekerja melakukan pekerjaan yang terlibat dalam proses produksi 
2. Material (bahan baku): segala sesuatu yang dipergunakan oleh perusahaan sebagai komponen produk yang akan diproduksi, terdiri dari bahan baku utama dan bahan baku pembantu

3. Machine (mesin): berbagai mesin dan peralatan yang digunakan dalam proses produksi

4. Method (metode): instruksi kerja atau perintah kerja yang harus diikuti dalam proses produksi.

Berikut adalah diagram sebab akibat untuk cacat retak rambut dan cacat patah

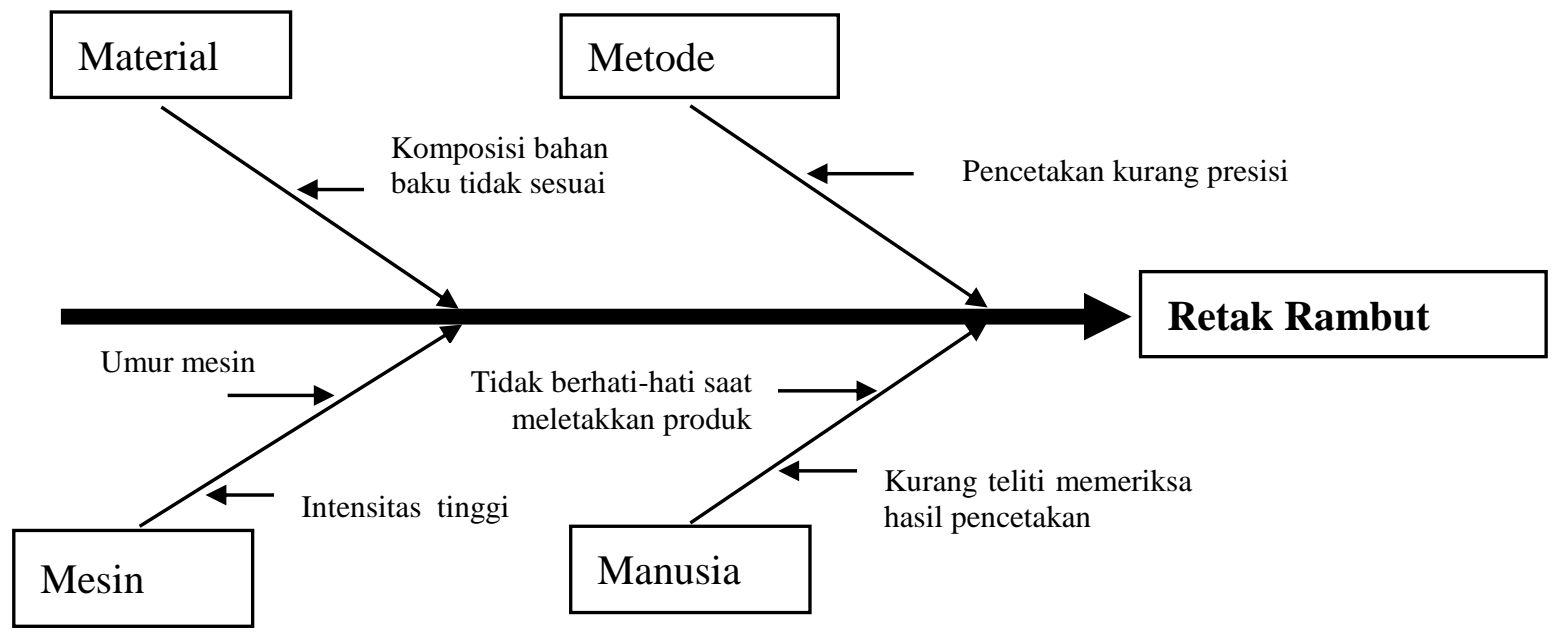

Gambar 5. Diagram Sebab Akibat untuk Jenis Cacat Retak Rambut

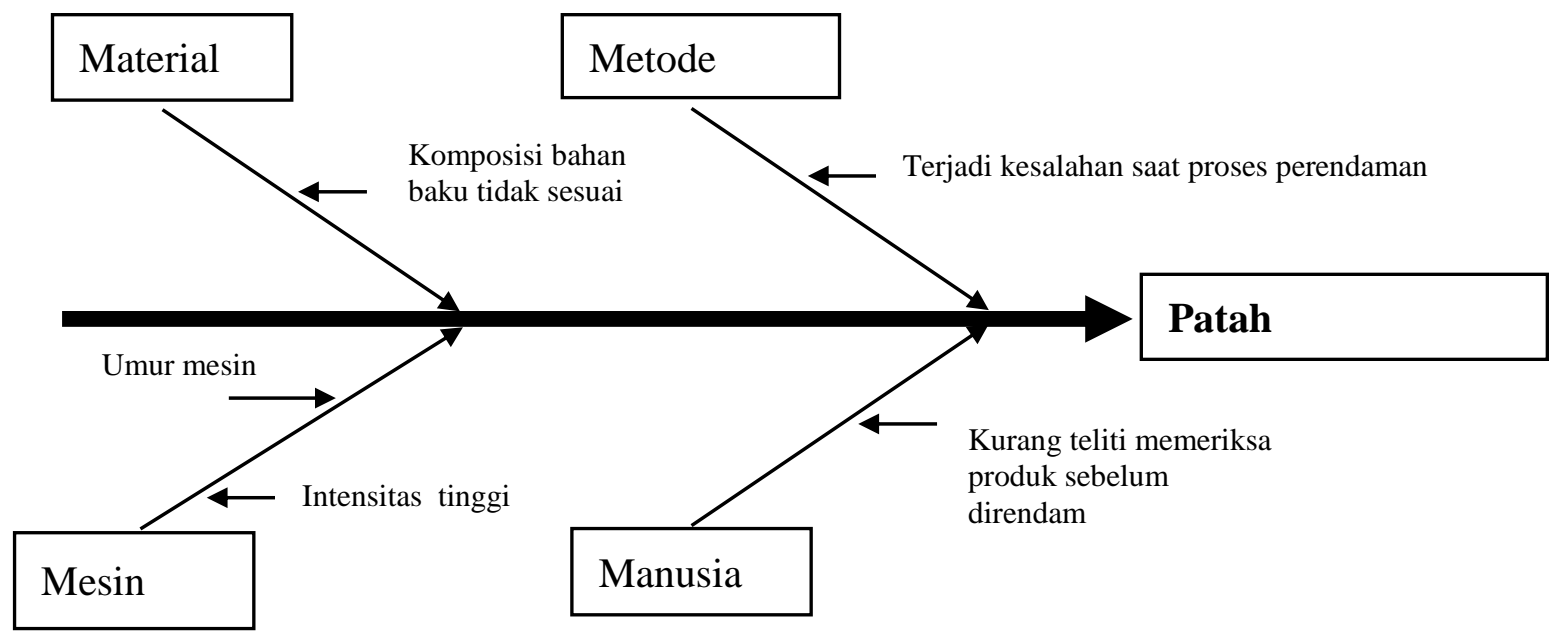

Gambar 6. Diagram Sebab Akibat untuk Jenis Cacat Patah 
Setelah dilakukan analisis faktor-faktor penyebab terjadinya produk cacat, maka dapat disusun usulan perbaikan sebagai berikut:

Tabel 5. Usulan Perbaikan

\begin{tabular}{|c|c|c|c|}
\hline No & Faktor Penyebab & Penyebab Kerusakan & Usulan Pencegahan \\
\hline 1 & Manusia & $\begin{array}{l}\text { - } \text { Kurang teliti dalam } \\
\text { pemeriksaan } \\
\text { produk } \\
\text { - Tidak berhati-hati } \\
\text { dalam meletakkan } \\
\text { produk }\end{array}$ & $\begin{array}{l}\text { Terdapat } \\
\text { pengawasan dan } \\
\text { arahan kepada } \\
\text { karyawan serta } \\
\text { melakukan pelatihan } \\
\text { kepada karyawan. }\end{array}$ \\
\hline 2 & Material & $\begin{array}{l}\text { Komposisi bahan baku } \\
\text { tidak sesuai }\end{array}$ & $\begin{array}{lr}\text { Memeriksa } & \text { kembali } \\
\text { komposisi } & \text { bahan } \\
\text { baku } & \text { sebelum } \\
\text { dilakukan proses } & \text { produksi dan terdapat } \\
\text { takaran yang jelas. }\end{array}$ \\
\hline 3 & Metode & 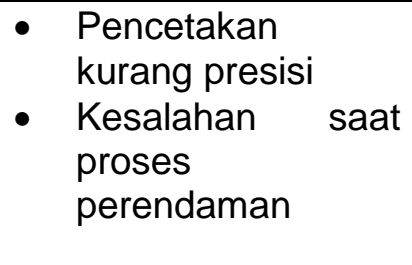 & $\begin{array}{l}\text { Terdapat SOP yang } \\
\text { jelas dalam proses } \\
\text { produksi } \\
\text { melakukan dan } \\
\text { pengawasan } \\
\text { terhadap operator. }\end{array}$ \\
\hline 4 & Mesin & $\begin{array}{l}\text { - Umur mesin yang } \\
\text { sudah tua } \\
\text { - } \quad \text { Intensitas } \\
\text { penggunaan tinggi }\end{array}$ & $\begin{array}{l}\text { Membuat jadwal } \\
\text { perbaikan mesin dan } \\
\text { jika diperlukan } \\
\text { membeli mesin baru. }\end{array}$ \\
\hline
\end{tabular}

\section{Kesimpulan}

Berdasarkan dari hasil penelitian maka dapat disimpulkan:

1. Terdapat dua jenis cacat pada produk genteng, yaitu cacat retak rambut dan patah. Jenis cacat terbanyak adalah retak rambut $(56,29 \%)$ daripada jenis cacat patah $(43,71 \%)$.

2. Berdasarkan peta kendali $p$ terlihat bahwa semua data dalam batas kendali.

3. Berdasarkan diagram sebab akibat dapat diketahui penyebab terjadinya produk cacat yaitu faktor manusia, material, metode dan mesin.

4. Untuk mengatasi permasalahan kualitas produk, maka dibuat usulan perbaikan berdasarkan faktor-faktor yang telah diuraikan pada diagram sebab akibat.

\section{Daftar Pustaka}

[1] Ahyari, Agus. (2000). Manajemen Produksi. Manajemen Produksi.BPFEUGM.Yogyakarta.

[2],[5] Montgomery,Douglas C. (2009). Introduction to Statistical Quality Control (6th ed.). John Wiley \& Sons.

[3] Devani, V., \& Wahyuni, F. (2016). Pengendalian Kualitas Kertas dengan Menggunakan Statistical Process Control di Paper Machine 3. Jurnal IImiah Teknik Industri , Vol. 15 (2), 87-93.

[4] Assauri. (2008). Manajemen Operasi dan Produksi Edisi Revisi. LP FE Ul.Jakarta.

[6] Bakhtiar,S.,Tahir,S.,\& Hasni,RA. (2013). Analisa Pengendalian Kualitas dengan Menggunakan Metode Statistical Quality Control. Malikussaleh Industrial Engineering Journal, Vol.2 No.1,29-36.

[7] Heizer,J.,\&Render,B. (2005). Manajemen Operasi Edisi 7. Salemba Empat. Jakarta. 